\title{
A novel CLDN16 mutation in a large family with familial hypomagnesaemia with hypercalciuria and nephrocalcinosis
}

\author{
Asma Deeb', Salima Atia Abood ${ }^{1}$, Job Simon ${ }^{1}$, Hormazdiar Dastoor ${ }^{2}$, Simon HS Pearce ${ }^{3}$ and John A Sayer ${ }^{3^{*}}$
}

\begin{abstract}
Background: Familial hypomagnesaemia with hypercalciuria and nephrocalcinosis is a rare tubulopathy leading to renal calcification and progressive renal failure.

Case presentation: We report a consanguineous Arab family (of Qatari origin) with 7 affected siblings with variable phenotypes including hypomagnesaemia, hypercalciuria, nephrocalcinosis and renal stones. Presenting features included haematuria and recurrent urinary tract infections. As the biochemical and clinical phenotypes of this family resembled familial hypomagnesaemia with hypercalciuria and nephrocalcinosis, we performed genetic investigation in order to provide a precise molecular diagnosis. We screened all coding regions of the CLDN16 gene and identified a novel mutation (c.G647A, p.R216H) which was found homozygously in the six severely affected cases, who manifested significant nephrocalcinosis, often nephrolithiasis and sometimes reduced GFR. Parents were both heterozygous for the mutation and, together with children carrying the mutation in its heterozygous state, exhibited mild or no biochemical phenotypes.
\end{abstract}

Conclusion: Mutations in CLDN16 underlie familial hypomagnesaemia with hypercalciuria and nephrocalcinosis but remain a rare cause of nephrocalcinosis and nephrolithiasis. Management includes reduction of hypercalciuria with thiazide diuretics, correction of serum magnesium and close monitoring of renal function given the significant risk of end stage renal failure with this inherited form of nephrocalcinosis.

Keywords: CLDN16, Claudin-16, Hypercalciuria, Hypocalcaemia, Hypomagnesaemia, Nephrocalcinosis, End stage renal disease

\section{Background}

Renal tubulopathies may present to a wide spectrum of clinicians with a variety of clinical, biochemical and radiological features. Renal tubular wasting of calcium and magnesium underlie the autosomal recessive disorder known as familial hypomagnesaemia with hypercalciuria and nephrocalcinosis (FHHNC) [1]. The clinical presentation often relates to the complications of severe hypercalciuria and nephrocalcinosis and may include haematuria, urinary tract infections and renal colic/calculi. The condition leads to progressive renal failure, often within the first two decades of life. Compound heterozygous or homozygous mutations in CLDN16, encoding a tight junction

\footnotetext{
* Correspondence: john.sayer@ncl.ac.uk

${ }^{3}$ Institute of Genetic Medicine, Newcastle University, International Centre for Life, Central Parkway, Newcastle upon Tyne, NE1 3BZ, UK

Full list of author information is available at the end of the article
}

protein expressed in the thick ascending limb of the loop of Henle, underlie this disorder.

We report a large consanguineous family who presented with a variety of clinical and biochemical features suggestive of familial hypomagnesaemia with hypercalciuria and nephrocalcinosis (FHHNC) in whom we have identified a novel homozygous CLDN16 mutation.

\section{Case presentation}

A large Qatari family (Figure 1A) presented with a variety of clinical features suggestive of an inherited tubulopathy. Clinical presentation of disease, even within the same family, was within a wide age range (Table 1 ).

The index case (II:1) presented 20 years of age with macroscopic haematuria. He had a past medical history of recurrent attacks of left loin pain typical of renal colic and was known to have renal stone disease and recurrent 
A

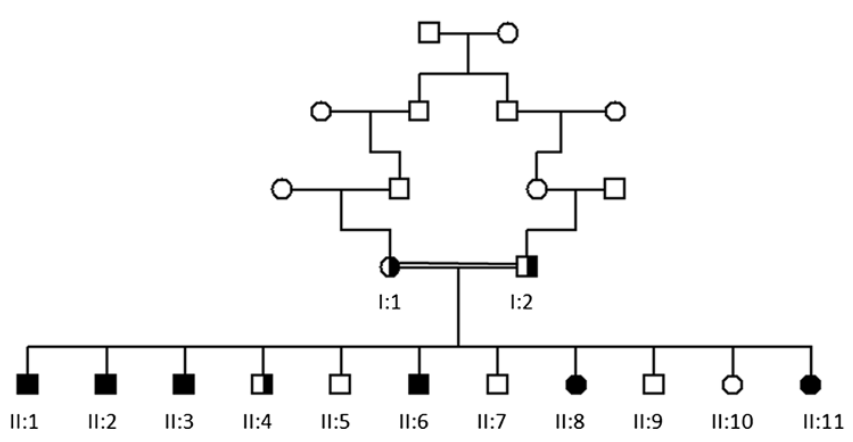

B

Father
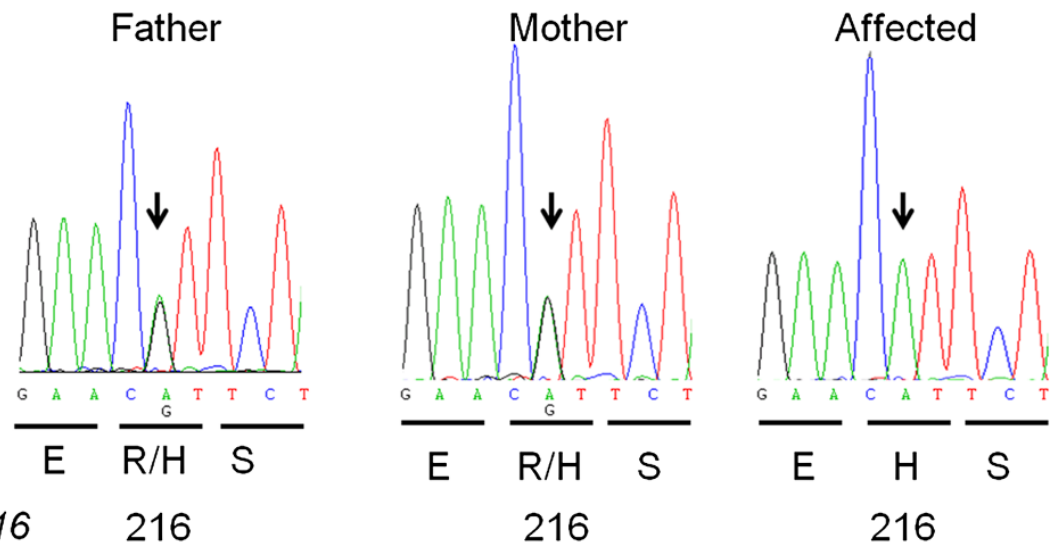

CLDN16 216

.

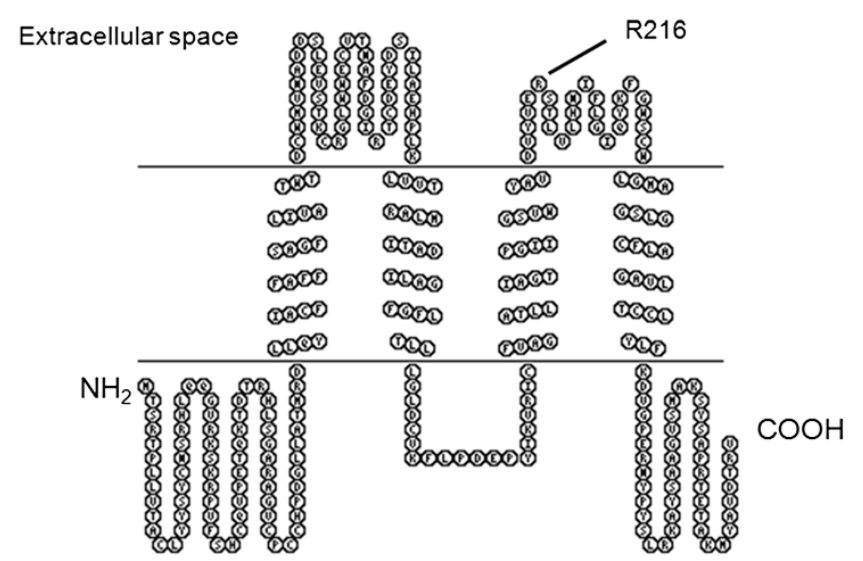

Cytoplasm

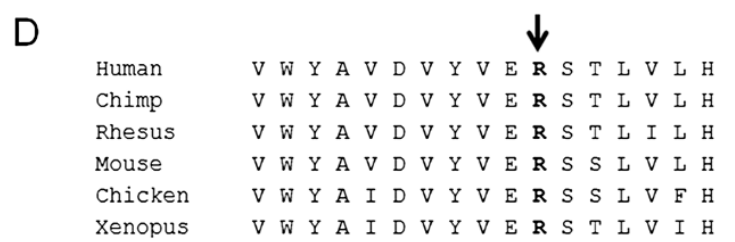

Figure 1 Molecular genetic investigation of the family. (A) Pedigree diagram of consanguineous multiplex family with homozygous and heterozygously affected members with Familial Hypomagnesaemia with Hypercalciuria and Nephrocalcinosis and CLDN16 mutations. Circles females, squares males, shaded = affected, half shaded = heterozygous carrier. (B) Mutational analysis and segregation demonstrates a c. G647A nucleotide substitution in exon 4 of CLDN16 leading to a missense change p. R216H. Amino acids and position are annotated below the chromatograms. (C) Claudin-16 protein (alias paracellin) model deduced from hydrophobicity plots and drawn using www.sacs.ucsf.edu/TOPO2. The mutated R216 in the second extracellular loop is annotated. (D) R216 residue (arrowed) is highly conserved from Human to Xenopus. 
Table 1 Clinical features at presentation

\begin{tabular}{|c|c|c|c|c|c|c|c|c|c|c|c|c|c|}
\hline $\begin{array}{l}\text { Family } \\
\text { member } \\
\text { ID }\end{array}$ & Age & Sex & Presentation & $\begin{array}{l}\text { Age of } \\
\text { presentation }\end{array}$ & $\begin{array}{l}\text { Serum calcium } \\
\text { (Reference range } \\
2.2-2.55 \mathrm{mmol} / \mathrm{l} \text { ) }\end{array}$ & $\begin{array}{l}\text { Serum magnesium } \\
\text { (Reference range } \\
0.7-1.05 \mathrm{mmol} / \mathrm{l} \text { ) }\end{array}$ & $\begin{array}{l}25(\mathrm{OH}) \text { vitamin } \mathrm{D} \\
\text { level } \\
\text { (Reference range } \\
75-250 \mathrm{mmol} / \mathrm{l})\end{array}$ & Hypercalciuria & Hypocitraturia & Nephrocalcinosis & $\begin{array}{l}\text { Renal } \\
\text { stone }\end{array}$ & $\begin{array}{l}\text { GFR } \\
\mathrm{mls} / \mathrm{min} / 1.73 \mathrm{~m}^{2}\end{array}$ & $\overline{\text { Genotype }}$ \\
\hline $\mathrm{l}: 1$ & 45 & $\mathrm{~F}$ & & - & 2.43 & 0.8 & N/A & Yes & $\mathrm{N} / \mathrm{A}$ & No & No & - & Het \\
\hline $1: 2$ & 48 & M & & - & 2.40 & N/A & N/A & No & $\mathrm{N} / \mathrm{A}$ & No & No & - & Het \\
\hline$\|: 1$ & 26 & M & $\begin{array}{l}\text { Macroscopic } \\
\text { haematuria }\end{array}$ & 20 years & 2.11 & 0.52 & 35.1 & Yes & Yes & Yes & Yes & 48 & Homo \\
\hline$\|: 2$ & 25 & M & $\begin{array}{l}\text { Recurrent UTI, } \\
\text { microscopic } \\
\text { haematuria }\end{array}$ & 20 years & 2.10 & 0.60 & N/A & Yes & Yes & Yes & No & 37 & Homo \\
\hline$\|: 3$ & 24 & M & $\begin{array}{l}\text { Loin pain, } \\
\text { passed a stone }\end{array}$ & 17 years & 2.13 & 0.59 & 29.4 & Yes & N/A & Yes & Yes & 67 & Homo \\
\hline$\|: 4$ & 23 & M & $\begin{array}{l}\text { Recurrent UTI, } \\
\text { microscopic } \\
\text { haematuria }\end{array}$ & 17 years & 2.25 & 0.85 & 21.3 & No & N/A & No & No & 126 & Het \\
\hline $11: 6$ & 22 & M & $\begin{array}{l}\text { Recurrent UTI, } \\
\text { microscopic } \\
\text { haematuria }\end{array}$ & 16 years & 2.08 & 0.45 & N/A & No & Yes & Yes & No & 37 & Homo \\
\hline $11: 8$ & 12 & $\mathrm{~F}$ & Loin pain & 7 years & 2.09 & 0.47 & 35.2 & No & Yes & Yes & No & 36 & Homo \\
\hline \|:11 & 3 & $\mathrm{~F}$ & Haematuria & 17 months & 2.40 & 0.76 & 61.0 & No & N/A & Yes & No & N/A & Homo \\
\hline
\end{tabular}

F, female; GFR, glomerular filtration rate; Het, heterozygous mutation; Homo, homozygous mutation; M, male; N/A, not available; UTI, urinary tract infection. 
urinary tract infections. Clinical examination revealed normal blood pressure and a BMI of $28.5 \mathrm{Kg} / \mathrm{m}^{2}$.

Biochemical investigations revealed hypercalciuria (24 h urine calcium $9.83 \mathrm{mmol} /$ day; reference range 2.5-8.5), hypomagnesaemia $(0.52 \mathrm{mmol} / \mathrm{l})$ and hypocalcaemia $(2.11 \mathrm{mmol} / \mathrm{l})$. Serum parathyroid hormone was raised at $16.96 \mathrm{pmol} / \mathrm{L}$ (reference range 1.3-6) in the context of low total vitamin D levels $(39.9 \mathrm{nmol} / \mathrm{l}$; reference range 75-200). There was also profound hypocitraturia (21 mg/day, reference range 290-888). Serum creatinine was elevated at $160 \mathrm{umol} / \mathrm{l}$ consistent with CKD stage 3 (Table 1 ).

A renal ultrasound demonstrated multiple fine echogenic cortical calcifications in both kidneys consistent with nephrocalcinosis and parenchymal renal calculi. The right kidney measured $9.8 \mathrm{~cm}$ in length and the left kidney measured $10.0 \mathrm{~cm}$. No cystic change was noted within the kidneys. An abdominal CT confirmed nephrocalcinosis (Figure 2A). Isotope imaging of the neck showed no evidence of a parathyroid adenoma.

The patient was managed with an increase in fluids, to reduce risk of stone formation and the addition of magnesium supplements and a thiazide diuretic in the form of hydrochlorothiazide $25 \mathrm{mg}$ daily.

A second family member (II:8) presented at 7 years of age with right sided loin pain. Biochemical investigations also revealed hypocalcaemia $(2.09 \mathrm{mmol} / \mathrm{l})$ and hypomagnesaemia $(0.56 \mathrm{mmol} / \mathrm{l})$ with a raised PTH $11 \mathrm{pmol} / \mathrm{l}$ in the context of a low total vitamin $\mathrm{D}$ level $(36 \mathrm{nmol} / \mathrm{l})$.
There was no evidence of hypercalciuria or hypermagnesuria (Table 1). Renal imaging (USS and CT scan) demonstrated nephrocalcinosis with bilateral symmetrical diffuse calyceal calcifications (Figure 2C). The child was similarly treated with magnesium supplementation and thiazide diuretics.

The discovery of these two cases of hypocalcaemia and hypomagnesaemia with hypercalciuria and nephrocalcinosis within the same family prompted a review of other affected family members, who had presented independently to other physicians and their parents. The clinical findings are detailed in Table 1 and renal imaging is shown in Figure 2. Family member II:11 is noteworthy given the early presentation at 17 months of age, following a urinary tract infection. USS of the renal tract, even at this young age, demonstrated nephrocalcinosis (Figure 2D).

\section{Genetic investigations}

Following informed consent from all adult patients/ relatives and from the parents or guardians of the patients who were under the age of 18, DNA samples were obtained and all coding regions of the CLDN16 gene were amplified and sequenced directly using Sanger sequencing.

We identified a novel missense mutation in exon 4 of the CLDN16 gene (c.G647A, p.R216H), located in the second extracellular loop (Figure $1 \mathrm{~B}, \mathrm{C}$ ). In silico prediction tools predict that the mutation is pathogenic. The
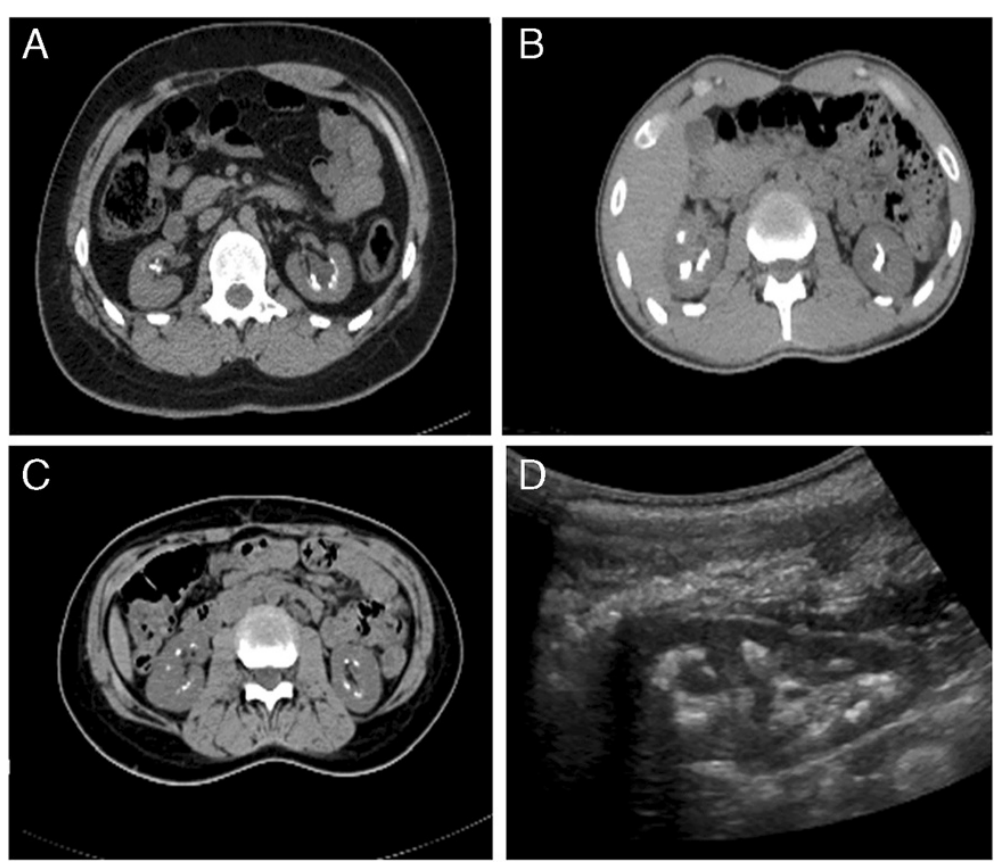

Figure 2 Imaging of the renal tract in affected members. A. CT scan showing bilateral nephrocalcinosis in II:1, aged 26 years. B. CT scan showing bilateral nephrocalcinosis in $11: 3$, aged 22 years. C. CT scan showing bilateral nephrocalcinosis in $11: 8$, aged 12 years. D. Renal USS demonstrating nephrocalcinosis in Il:11, aged 3 years. 
variant was absent from both the 1000 Genomes and Exome Variant Server databases. The Arginine residue is highly conserved (Figure 1D). Interestingly, a R216C mutation, affecting the same residue, has been previously reported $[2,3]$. This $\mathrm{R} 216 \mathrm{C}$ sequence variant was not observed in 100 European and 50 Japanese control alleles [2,3].

Mutations in CLDN16 (alias PCLN1) cause the autosomal recessive condition familial hypomagnesaemia with hypercalciuria and nephrocalcinosis (FHHNC) [1]. The phenotype includes renal magnesium and calcium wasting secondary to defects in the thick ascending limb reabsorption of calcium and magnesium, which leak through defective tight junctions owing to mutations in CLDN16 encoding claudin-16. The expression of claudin-16 is limited to the tight junctions of renal epithelial cells of the thick ascending limb of the loop of Henle [4]. The clinical presentation may be in childhood or adolescence with symptomatic hypocalcaemia [3,5-8].

As seen in this family, nephrocalcinosis and recurrent nephrolithiasis are also seen. Nephrocalcinosis may contribute to a renal tubular acidification defect and to the inability to concentrate urine and hypokalaemia may also be a feature. Our family was typical of many cases of FHHNC, with affected members presenting with recurrent urinary tract infections. Other features can include polyuria/polydipsia, rickets, haematuria, muscular tetany, seizures, failure to thrive, vomiting, and abdominal pain $[9,10]$. Additional biochemical findings can include hypocitraturia [11], increased parathyroid hormone (PTH) levels (independent of GFR) [5], and hyperuricaemia. Worryingly, FHHNC is often complicated by progressive renal failure which occurs during childhood or adolescence. Within this family there was a variable loss of renal function, with some family members with significant renal impairment at a young age (Table 1).

The phenotype of heterozygous carriers of CLDN16 mutations is not totally benign. Hypercalciuria, as seen in this family, and even nephrolithiasis may be seen in heterozygous "carriers" of mutations $[5,10]$.

Mutations in the CLDN19 gene (encoding a related tight junction protein, Claudin-19) can produce the same biochemical phenotype as CLDN16 mutations [3]. However, patients with CLDN19 mutations had additional phenotypes including eye involvement and severe visual impairment.

Mutational analysis has allowed the identification of $~ 50$ different mutations of CLDN16. In one study of 32 patients, nearly half had a L151F missense mutation. This mutational hot spot was proposed to be due to a founder effect (Germany and Eastern European countries) [10]. The $\mathrm{R} 216 \mathrm{H}$ mutation, affecting the second extracellular loop, found in this family is novel. The extracellular loops are important for interactions between claudin molecules of neighbouring cells [12]. Mutations affecting the same amino acid have been described previously. An R216C mutation has been described in a heterozygous state, in combination with a R149Q missense mutation in a Japanese child presenting at 5 years of age with haematuria, hypercalciuria, and nephrocalcinosis $[2,3]$. In addition, a R216T mutation has also been described [4,13]. In functional studies the R216T mutation was shown to mis-traffic to the tight-junction [13] although was seen to correctly localise to the tight junction, with a magnesium transport defect, by other investigators [4].

Other inherited disorders that may present in childhood with hypomagnesaemia include Gitelman's syndrome [14], familial hypomagnesaemia with secondary hypocalcaemia $(\mathrm{HSH})$ [15] and autosomal dominant hypomagnesaemia [16]. Gitelman's syndrome is renal salt-wasting alkalosis characterised by a hypokalaemic metabolic alkalosis [14]. Gitelman's patients typically have hypocalciuria and do not exhibit nephrocalcinosis [17]. Mutations in SLC12A3 encoding the thiazide-sensitive sodium-chloride co-transporter underlie this disease [14]. Familial hypomagnesaemia with secondary hypocalcaemia $(\mathrm{HSH})$ is a rare autosomal recessive disease caused by mutations in TRPM6 an apical magnesium uptake channel in the intestine and distal convoluted tubule of the kidney [18]. The biochemical phenotype usually reveals an extremely low serum magnesium. There is secondary low serum calcium levels, thought to be due to an impaired synthesis and/or release of PTH. Again, nephrocalcinosis would not be an expected feature of patients with TRPM6 mutations. Autosomal dominant hypomagnesaemia is a renal magnesium wasting tubulopathy. A mild hypomagnesaemia occurs and an associated hypocalciuria. Mutations in the FXYD2 gene are responsible for this disorder [16].

Another condition that may cause diagnostic confusion with FHHNC is autosomal dominant hypocalcaemia $(\mathrm{ADH})$ secondary to activating mutations of the calciumsensing receptor that lead to hypocalcaemia with hypercalciuria [19]. Hypomagnesaemia can be a feature of this condition and typically serum PTH is in the low-normal range. Here the inheritance pattern is autosomal dominant and the majority of patients are asymptomatic and are diagnosed as adults when hypocalcaemia is noted as an incidental finding. Some patients exhibit a salt wasting phenotype with hypokalaemia, mimicking Bartter's syndrome [20]. In $\mathrm{ADH}$, vitamin $\mathrm{D}$ and calcium supplementation worsen the hypercalciuria, and may lead to increased nephrocalcinosis and calcium stone formation. Genetic testing of the CASR gene allows a molecular diagnosis to be made [21].

For the medical management of cases of FHHNC, attention should be given to the management of the biochemical 
abnormalities. Thiazide diuretics can reduce effectively the calcium excretion in patients with FHHNC [22] and magnesium supplementation should be given. In addition, Vitamin D and calcium supplementation may be required. There was evidence of vitamin D deficiency in the family we describe. Limited sunlight exposure and poor oral intake of vitamin D are common risk factors for vitamin D deficiency in the Middle East [23]. The dramatic loss of renal function in patients with CLDN16 mutations is a noteworthy and worrying feature, and the aetiology of which is currently unclear [3]. It can be speculated that the dramatic nephrocalcinosis is contributory, yet there are other renal disorders with nephrocalcinosis that do not show similar rates of decline in renal function [24]. Strategies to measure and optimise renal function are important. Urinary tract infections and obstructive calculi should be treated promptly to prevent ascending infections, obstruction and further renal insults. As expected from an inherited tubulopathy, following renal transplantation, magnesium and calcium regulation normalize, indicating that FHHNC patients are ideal candidates for renal transplantation [5].

\section{Conclusions}

In summary, in we have made a molecular genetic diagnosis of a CLDN16 mutation in a large consanguineous family with nephrocalcinosis, renal stones and renal impairment. Age and clinical features at presentation can be very variable, even from within the same family. A molecular genetic diagnosis enables a screen of other family members at risk of disease and allows management of urinary electrolyte abnormalities to prevent further deterioration in renal function and renal stone formation.

\section{Consent}

Written informed consent to publish this case report was obtained for all adult patients, and from the parents or guardians of the patients who were under the age of 18 . A copy of the written consent is available for review by the Editor-in-Chief of this journal.

\section{Competing interests}

The authors declare that they have no competing interests.

\section{Authors' contributions}

AD carried out clinical data reviews and drafted the manuscript; SAA, JS, and HD participated in the coordination of the clinical and radiological data and helped draft the manuscript; SHSP and JAS conceived the study, performed sequence analysis and drafted the manuscript. All authors read and approved the final manuscript.

\section{Acknowledgements}

JAS is funded by the Northern Counties Kidney Research fund and Kidney Research UK.

\section{Author details}

${ }^{1}$ Endocrinology Department, Mafraq Hospital, AbuDhabi, United Arab Emirates. ${ }^{2}$ Nephrology Department, Mafraq Hospital, AbuDhabi, United Arab
Emirates. ${ }^{3}$ Institute of Genetic Medicine, Newcastle University, International Centre for Life, Central Parkway, Newcastle upon Tyne, NE1 3BZ, UK.

Received: 26 March 2013 Accepted: 5 December 2013

Published: 10 December 2013

\section{References}

1. Simon DB, Lu Y, Choate KA, Velazquez H, Al-Sabban E, Praga M, Casari G, Bettinelli A, Colussi G, Rodriguez-Soriano J, et al: Paracellin-1, a renal tight junction protein required for paracellular Mg2+ resorption. Science 1999, 285:103-106.

2. Tajima T, Nakae J, Fujieda K: Two heterozygous mutations of CLDN16 in a Japanese patient with FHHNC. Pediatr Nephrol 2003, 18:1280-1282.

3. Konrad M, Hou J, Weber S, Dotsch J, Kari JA, Seeman T, Kuwertz-Broking E, Peco-Antic A, Tasic V, Dittrich K, et al: CLDN16 genotype predicts renal decline in familial hypomagnesemia with hypercalciuria and nephrocalcinosis. J Am Soc Nephrol 2008, 19:171-181.

4. Kausalya PJ, Amasheh S, Gunzel D, Wurps H, Muller D, Fromm M, Hunziker W: Disease-associated mutations affect intracellular traffic and paracellular Mg2+ transport function of Claudin-16. J Clin Invest 2006, 116:878-891.

5. Praga M, Vara J, Gonzalez-Parra E, Andres A, Alamo C, Araque A, Ortiz A, Rodicio JL: Familial hypomagnesemia with hypercalciuria and nephrocalcinosis. Kidney Int 1995, 47:1419-1425.

6. Nicholson JC, Jones CL, Powell HR, Walker RG, McCredie DA: Familial hypomagnesaemia-hypercalciuria leading to end-stage renal failure. Pediatr Nephrol 1995, 9:74-76.

7. Benigno V, Canonica CS, Bettinelli A, von Vigier RO, Truttmann AC, Bianchetti MG: Hypomagnesaemia-hypercalciuria-nephrocalcinosis: a report of nine cases and a review. Nephrol Dial Transplant 2000, 15:605-610.

8. Muller D, Kausalya PJ, Bockenhauer D, Thumfart J, Meij IC, Dillon MJ, van't Hoff W, Hunziker W: Unusual clinical presentation and possible rescue of a novel claudin-16 mutation. J Clin Endocrinol Metab 2006, 91:3076-3079.

9. Michelis MF, Drash AL, Linarelli LG, De Rubertis FR, Davis BB: Decreased bicarbonate threshold and renal magnesium wasting in a sibship with distal renal tubular acidosis. (Evaluation of the pathophysiological role of parathyroid hormone). Metabolism 1972, 21:905-920.

10. Weber S, Schneider L, Peters M, Misselwitz J, Ronnefarth G, Boswald M, Bonzel KE, Seeman T, Sulakova T, Kuwertz-Broking E, et al: Novel paracellin-1 mutations in 25 families with familial hypomagnesemia with hypercalciuria and nephrocalcinosis. J Am Soc Nephrol 2001, 12:1872-1881.

11. Rodriguez-Soriano J, Vallo A: Pathophysiology of the renal acidification defect present in the syndrome of familial hypomagnesaemiahypercalciuria. Pediatr Nephrol 1994, 8:431-435.

12. Furuse M, Sasaki H, Tsukita S: Manner of interaction of heterogeneous claudin species within and between tight junction strands. J Cell Biol 1999, 147:891-903

13. Hou J, Paul DL, Goodenough DA: Paracellin-1 and the modulation of ion selectivity of tight junctions. J Cell Sci 2005, 118:5109-5118.

14. Simon DB, Nelson-Williams C, Bia MJ, Ellison D, Karet FE, Molina AM, Vaara I, Iwata F, Cushner HM, Koolen M, et al: Gitelman's variant of Bartter's syndrome, inherited hypokalaemic alkalosis, is caused by mutations in the thiazidesensitive Na-Cl cotransporter. Nat Genet 1996, 12:24-30.

15. Schlingmann KP, Weber S, Peters M, Niemann Nejsum L, Vitzthum H, Klingel K, Kratz M, Haddad E, Ristoff E, Dinour D: Hypomagnesemia with secondary hypocalcemia is caused by mutations in TRPM6, a new member of the TRPM gene family. Nat Genet 2002, 31:166-170.

16. Meij IC, Koenderink JB, De Jong JC, De Pont JJ, Monnens LA, Van Den Heuvel LP, Knoers NV: Dominant isolated renal magnesium loss is caused by misrouting of the Na+, K+-ATPase gamma-subunit. Ann N Y Acad Sci 2003, 986:437-443.

17. Sayer JA, Pearce SH: Diagnosis and clinical biochemistry of inherited tubulopathies. Ann Clin Biochem 2001, 38:459-470.

18. Chubanov V, Waldegger S, Mederos Y, Schnitzler M, Vitzthum H, Sassen MC, Seyberth HW, Konrad M, Gudermann T: Disruption of TRPM6/TRPM7 complex formation by a mutation in the TRPM6 gene causes hypomagnesemia with secondary hypocalcemia. Proc Natl Acad Sci U S A 2004, 101:2894-2899.

19. Pearce SH, Williamson C, Kifor O, Bai M, Coulthard MG, Davies M, Lewis-Barned N, McCredie D, Powell H, Kendall-Taylor P, et al: A familial syndrome of hypocalcemia with hypercalciuria due to mutations in the calcium-sensing receptor. N Engl J Med 1996, 335:1115-1122. 
20. Sayer JA, Pearce SH: Extracellular calcium-sensing receptor dysfunction is associated with two new phenotypes. Clin Endocrinol (Oxf) 2003, 59:419-421.

21. Hendy GN, D'Souza-Li L, Yang B, Canaff L, Cole DE: Mutations of the calcium-sensing receptor (CASR) in familial hypocalciuric hypercalcemia, neonatal severe hyperparathyroidism, and autosomal dominant hypocalcemia. Hum Mutat 2000, 16:281-296.

22. Zimmermann B, Plank C, Konrad M, Stohr W, Gravou-Apostolatou C, Rascher W, Dotsch J: Hydrochlorothiazide in CLDN16 mutation. Nephrol Dial Transplant 2006, 21:2127-2132.

23. Bener A, Al-Ali M, Hoffmann GF: High prevalence of vitamin D deficiency in young children in a highly sunny humid country: a global health problem. Minerva Pediatr 2009, 61:15-22.

24. Konrad M, Weber S: Recent advances in molecular genetics of hereditary magnesium-losing disorders. J Am Soc Nephrol 2003, 14:249-260.

doi:10.1186/1756-0500-6-527

Cite this article as: Deeb et al: A novel CLDN16 mutation in a large family with familial hypomagnesaemia with hypercalciuria and nephrocalcinosis. BMC Research Notes 2013 6:527.

\section{Submit your next manuscript to BioMed Central and take full advantage of:}

- Convenient online submission

- Thorough peer review

- No space constraints or color figure charges

- Immediate publication on acceptance

- Inclusion in PubMed, CAS, Scopus and Google Scholar

- Research which is freely available for redistribution 